\title{
BRPKM
}

Buletin Riset Psikologi dan Kesehatan Mental

http://e-journal.unair.ac.id/index.php/BRPKM

e-ISSN: 2776-1851

ARTIKEL PENELITIAN

\section{Hubungan antara Body Image dan Perilaku Diet pada Wanita Dewasa Awal}

IVANA MANURUNG*

Fakultas Psikologi Universitas Airlangga

\begin{abstract}
ABSTRAK
Tujuan dari penelitian ini adalah untuk mengetahui hubungan antara body image dengan perilaku diet pada wanita dewasa usia 20-40 tahun. Penelitian ini menunjukkan bahwa body image yang dilakukan merupakan bentuk ketidakpuasan terhadap bentuk tubuh yang dimiliki pada wanita dewasa awal. Penelitian ini dilakukan pada 92 partisipan wanita dewasa awal. Multidimensional Body Self-Regulations Questionnare (MBRSQ) dan skala perilaku diet merupakan alat ukur yang digunakan. Analisis data dilakukan dengan teknik Product Moment dengan bantuan SPSS 21.0 for Windows. Hasil dari penelitian ini menunjukan bahwa terdapat korelasi yang signifikan antara body image dan perilaku diet $(\mathrm{r}=0,451$, $\mathrm{p}=0,00$ ). Korelasi bersifat positif yang berarti semakin tinggi body image negatif maka semakin tinggi juga perilaku diet yang dilakukan wanita dewasa awal.
\end{abstract}

Kata kunci: body image, dewasa awal, perilaku diet

\section{ABSTRACT}

The purpose of this study was to determine the relationship between body image and diet behavior in adult women aged 20-40 years. This study shows that body image is a form of body shape dissatisfaction that is owned by early adult women. This study was conducted on 92 early adult female participants. The Multidimensional Body Self-Regulation Questionnare (MBRSQ) and the dietary behavior scale are the measuring tools used. Data analysis was carried out using the Product Moment technique with the help of SPSS 21.0 for Windows. The results of this study indicate that there is a significant relationship between body image and dietary behavior $(r=0.451, p=0.00)$. The correlation is positive, which means that the higher the negative body image, the higher the dietary behavior of early adult women.

Keywords: body image, diet behavior, early adulthood

Buletin Penelitian Psikologi dan Kesehatan Mental (BRPKM), 2021, Vol. 1(2), 1126-1131

*Alamat korespondensi: Fakultas Psikologi Universitas Airlangga, Kampus B Universitas Airlangga Jalan Airlangga 4-6 Surabaya 60286. Surel: ivana.manurung-2017@psikologi.unair.ac.id

Naskah ini merupakan naskah dengan akses terbuka dibawah ketentuan the Creative Common Attribution License (CC-BY-4.0) (http://creativecommons.org/licenses/by/4.0), sehingga penggunaan, distribusi, reproduksi dalam media apapun atas artikel ini tidak dibatasi, selama sumber aslinya disitir dengan baik. 


\section{PENDAHULUAN}

Memiliki tubuh yang ideal menurut wanita yaitu memiliki badan yang kurus dan langsing, hal ini terjadi pada perkembangan dewasa awal khususnya wanita. Dariyo (2003) menjelaskan bahwa permasalahan ini terjadi pada perkembangan dewasa awal karena perubahan fisik khususnya wanita. Hal ini dipengaruhi oleh body image yang dimiliki pada tiap individu, ketika individu memiliki body image negatif, ia memiliki keyakinan akan bentuk tubuh yang dimiliki tidak memenuhi standar pribadinya, sehingga individu menilai tubuhnya dengan rendah, akibatnya menghambat dalam perkembangan membangun hubungan interpersonal serta membangun hubungan positif dengan orang lain (Rombe, 2013). Perkembangan wanita dewasa awal ini lebih memfokuskan pada penampilan dan berat badan, hal ini karena merupakan bagian dari rasa percaya diri dan harga diri, hal ini membuat wanita menampilkan bentuk tubuh yang dimiliki dengan sebaik-baiknya. Grogan (2008) juga menemukan bahwa pada masa dewasa awal ini, masih ada individu yang masih tidak puas dan memandang gambaran tubuh dengan negatif. Menurut Najam \& Ashfaq (2012) ketidakpuasan bentuk tubuh banyak dialami oleh wanita daripada laki-laki. Grogan (2008) menjelaskan bahwa wanita cenderung merubah pada bagian tertentu agar memenuhi standar di lingkungan sosial. Penelitian yang dilakukan oleh Erdianto (2009) terhadap perilaku diet yang dilakukan oleh wanita dewasa awal meskipun individu memiliki IMT normal tetapi individu tersebut tetap melakukan diet. Alasan individu melakukan diet yaitu takut jika berat badan naik dan tidak proporsional. Brennan, Lalonde, \& Bain (2010) menyatakan bahwa ketidakpuasan bentuk tubuh merupakan permasalahan yang didominasi oleh wanita.

Polivy \& Herman (1978) menjelaskan beberapa faktor perilaku diet yaitu jenis kelamin yang berpengaruh di setiap gizi yang diperlukan, selanjutnya usia yang mana faktor usia ini berpengaruh karena setiap perkembangan harus mencukupi kebutuhan gizi yang baik, kemudian aktivitas yaitu setiap setiap individu memiliki kebutuhan gizi yang berbeda ditentukan dengan aktivitas yang dilakukan serta aspek-aspek pada perilaku diet yaitu eksternal, emosional, serta pengekangan. Husna (2013) membagi jenis perilaku diet menjadi dua yaitu perilaku diet sehat dan tidak sehat. Perilaku diet yang sehat yaitu mengurangi asupan makan atau mengontrol kalori, mengurangi camilan, dan melakukan aktivitas fisik seperti olahraga. Perilaku diet tidak sehat yaitu dengan sengaja melewatkan waktu makan, serta mengkonsumsi obat-obatan pelangsing tubuh.

Polivy \& Herman (1978) menemukan bahwa perilaku diet merupakan upaya menurunkan berat badan dengan cara tertentu dan fokus pada pengaturan pola makan pelaku diet. Sejalan dengan ini, Siregar (2009) menyatakan bahwa perilaku diet yaitu perilaku yang memiliki aturan dalam mengonsumsi makanan dan minuman oleh seseorang secara rutin guna menjaga kesehatan serta tindakan atau perbuatan yang dapat dipelajari dan diamati, perilaku diet yang di lakukan ini karena adanya penilaian yang dimiliki oleh individu terkait body image.

Menurut Muhith (2015), body image yang dimiliki atas bentuk tubuh yang dimiliki serta penlilaaian yang muncul. Body image dianggap sebagai pemikiran yang dinamis dan dapat dipengaruhi oleh faktor-faktor seperti pengalaman interpersonal, kepribadian, dan norma sosial dan budaya (Mountford \& Koskina, 2015). Sedangkan Naimah (2008) mengatakan body image sebagai sikap individu terkait bentuk tubuh, ukuran, serta estetika berdasarkan evaluasi individu juga pengalaman efektif terhadap karakter fisiknya. Kemudian menurut Cash \& Pruzinsky (2002, dalam Grogan, 2008) body image adalah sikap individu yang berupa penilaian terhadap tubuh yang dimiliki, penilaian ini berupa positif dan negatif. 
Menurut Cash \& Pruzinsky (2002) body image terdiri dari beberapa dimensi, yaitu evaluasi penampilan (Appearance evaluation), orientasi penampilan (Appearance orientation), kepuasan terhadap bagian tubuh (Body area satisfaction), kecemasan menjadi gemuk (Overweight preoccupation), klasifikasi ukuran tubuh (Self-classified weight).

Studi oleh Yulianti \& Indriati (2015) menemukan bahwa individu dengan body image yang positif akan lebih menghargai bentuk tubuhnya, cenderung memiliki perilaku positif, serta hubungan sosial yang sehat. Sedangkan, seseorang yang memiliki body image negatif akan timbul permasalahan pada rasa percaya dirinya, sehingga memunculkan rasa tidak puas pada kondisi dirinya. Penilaian yang dimunculkan oleh wanita dewasa awal tentang body image. Permasalahan pada penelitian ini yaitu ketika wanita dewasa awal melakukan perilaku diet karena adanya body image negatif, hal ini menghambat perkembangan individu untuk menjalin komunikasi dan menjalin hubungan, maka dari itu perilaku diet sangat penting dilakukan oleh wanita dewasa awal untuk merasa dihargai dalam sebuah kelompok besar.

Penelitian yang dilakukan ini agar mengetahui apakah ada hubungan signifikan antara body image dan perilaku diet pada wanita dewasa awal.

\section{Desain Penelitian}

\section{METODE}

Menggunakan pendekatan kuantitatif-survei. Penulis menggunakan pendekatan kuantitatif dengan menghasilkan data berbentuk angka yang diperoleh dari jawaban partisipan melalui survei dengan memberikan pertanyaan berupa kuesioner. Pertanyaan ini telah disusun melalui Google Form dan disebar melalui online. Kuesioner penelitian ini dibagi menjadi dua yaitu Multidimensional Body Self-Regulations Questionnaire (MBSRQ) untuk mengukur variabel body image dan perilaku diet untuk variabel perilaku diet. Alat ukur ini telah diadaptasi oleh peneliti sebelumnya, yaitu Dewi \& Adriyanti (2020). Analisis data yang dilakukan menggunakan product moment dengan bantuan SPSS.21.0 for Windows. Analisis ini digunakan untuk mengetahui hubungan antara body image dan perilaku diet pada wanita dewasa awal.

\section{Partisipan}

Menggunakan partisipan wanita dewasa awal, berusia 20-40 tahun, sedang diet, dan memiliki ketidakpuasan bentuk tubuh. Teknik sampling yang digunakan adalah purposive sampling yaitu, pemilihan metode partisipan sesuai dengan karakteristik yang diharapkan peneliti (Neuman, 2007). Penelitian ini menggunakan 92 partisipan.

\section{Pengukuran}

Pengukuran body image ini menggunakan Multidimensional Body Self-Regulations Questionnaire (MBSRQ) milik Cash \& Pruzinsky (2002) yang telah diadaptasi oleh Devegga (2017) yang terdiri dari 27 aitem, skala alat ukur likert yang terdiri dari 4 jawaban yaitu, "1= Sangat Tidak Sesuai - 4= Sangat Sesuai" serta mencakup favorable dan unfavorable. Sedangkan pengukuran perilaku diet menggunakan perilaku diet milik Andea (2010) yang telah diadaptasi oleh Devegga (2017), terdiri dari 25 aitem, skala alat ukur likert yangiterdiri dari 4 jawaban, yaitu "1= Sangat Tidak Sesuai - 4= Sangat Sesuai" serta mencakup favorable dan unfavorable. 
Validitas yang digunakan yaitu internal validity dan validitas isi (content validity) oleh Husna (2013) menggunakan alpha cronbach, nilai reliabilitas sebesar 0,922. Kemudian variabel perilaku diet memiliki n nilai validitas berkisar antara 0,432-0,595, kemudian uji reliabilitas menggunakan alpha cronbach nilai reliabilitas sebesar 0,897 .

\section{Analisis Data}

Uji Product Moment digunakan untuk melihat hubungan antara body image dan perilaku diet. Seluruh analisis dilakukan dengan bantuan program SPSS 21.0 for Windows.

\section{HASIL PENELITIAN}

Hasil analisis deskriptif menunjukan sebagian besar partisipan memiliki body image negatif yaitu sebanyak 63 orang (68\%), sedangkan partisipan yang mengalami body image positif sebanyak 29 orang (32\%), selain itu sebagian partisipan penelitian mengalami perilaku diet kategori tinggi sebanyak 50 orang (50\%), selain itu dalam kategori sedang sebanyak 7 orang (8\%) dan dalam kategori rendah sebanyak 35 orang (38\%).

Hasil analisis korelasi diketahui bahwa body image dan perilaku diet berkorelasi secara positif dan cenderung tinggi $(\mathrm{r}(451)=0,00 ; p<0.05)$ dengan perilaku diet. Hal ini menunjukan bahwa $\mathrm{H}_{0}$ ditolak dan $\mathrm{H}_{\mathrm{a}}$ diterima, dengan artian bahwa terdapat hubungan antara body image dengan perilaku diet.

\section{DISKUSI}

Hasil dari pengambilan data yang dilakukan menunjukan skor korelasi, hal ini menunjukan Ho ditolak serta adanya hubungan korelasi yang positif antara variabel body image dan perilaku diet. Penjelasan dari hubungan yang positif menunjukan jika semakin tinggi body image negatif maka tinggi pula perilaku diet yang dilakukan. Berdasarkan nilai korelasi yang dimiliki dapat menjelaskan mengenai kuat atau lemahnya hubungan antara kedua variabel tersebut dan hasil yang diperoleh tidak memiliki tanda negatif (-), hal ini menunjukan bahwa data koefisien yang positif, sehingga adanya suatu hubungan korelasi yang positif antara variabel body image dan perilaku diet itu searah. Kemudian dapat disimpulkan bahwa memiliki data yang positif sehingga, adanya suatu hubungan antara body image dengan perilaku diet pada dewasa awal.

Maka hal ini sesuai dengan penelitian Irawan \& Safitri (2014) terkait hubungan antara body image dan perilaku diet memiliki korelasi yang positif, sehingga semakin tinggi body image negatif yang dimiliki maka akan semakin tinggi perilaku diet yang dilakukan pada diri individu, begitupun sebaliknya semakin rendah body image negatif yang dimiliki maka semakin rendah perilaku diet yang dilakukan oleh individu. Juga penelitian oleh Navia dkk. (2003)bahwa 234 mahasiswi menurunkan berat badan karena memiliki perspepsi tentang bentuk tubuh yang nengatif. Papalia (2009) juga menjelaskan bahwa kepedulian body image yang sempurna dapat menyebabkan usaha pengendalian berat badan yang berlebihan. Sehingga, partisipan melakukan berbagai cara untuk mendapatkan bentuk tubuh yang ideal. Seseorang yang memiliki body image negatif akan timbul permasalahan pada rasa percaya dirinya, sehingga memunculkan rasa tidak puas pada kondisi dirinya. Ifdil, Denich, \& Ilyas (2017) menjelaskan bahwa penampilan fisik berpengaruh pada kepercayaan diri didasarkan bagaimana bentuk fisik dan peniliaian atas bentuk tubuh yang dimiliki. 


\section{SIMPULAN}

Berdasarkan hasil penelitian yang telah dilakukan oleh peneliti, dapat diambil kesimpulan bahwa terdapat hubungan yang signifikan antara body image dan perilaku diet pada wanita dewasa awal. Dari uji hipotesis tersebut, menghasilkan bahwa adanya hubungan antara body image dan perilaku diet karena Ha diterima dan Ho ditolak. Kemudian, uji korelasi menunjukan angka 0,451 yang berarti koefisien positif karena pada hasil korelasi variabel body image dan perilaku diet tidak ada tanda negatif (-). Hal ini menggambarkan bahwa body image yang dimiliki pada masa dewasa awal mempengaruhi perilaku diet

\section{UCAPAN TERIMAKASIH}

Terima kasih penulis ucapkan kepada Allah SWT, keluarga, dan teman-teman yang telah mendukung serta membantu penulis selama proses penelitian. Terima kasih juga saya ucapkan kepada peneliti sebelumnya yang telah memberikan izin untuk pemakaian alat ukur body image dan perilaku diet.

\section{DEKLARASI POTENSI TERJADINYA KONFLIK KEPENTINGAN}

Ivana Manurung tidak bekerja, menjadi konsultan, memiliki saham, atau menerima dana dari perusahaan atau organisasi manapun yang mungkin akan mengambil untung dari diterbitkannya naskah ini.

\section{PUSTAKA ACUAN}

Andea, R. (2010). Hubungan Antara Perilaku dan Perilaku Diet pada Remaja. Skripsi Fakultas Psikologi $U S U$.

Brennan, M., Lalonde, C., \& Bain, J. (2010). Body image perceptions: do gender differences exist?. Psi Chi Journal of Psychological Research. 15. 130-138. 10.24839/1089-4136.JN15.3.130.

Cash, T. F., \& Pruzinsky, T. (2002). Body Image: A Handbook of Theory Research and Clinical. New York: Guilford Publication.

Dariyo, A. (2003). Psikologi Perkembangan Dewasa Muda. Jakarta: Grasindo.

Devegga, Merrynta. (2017). Hubungan antara Body Image dan Perilaku Diet pada Remaja Putri. Repository UKSW. https://repository.uksw.edu/handle/123456789/13155

Dewi, G. K., \& Adriyanti, E. Z. (2020). Hubungan body image dan diet terhadap status gizi remaja putri di smk analis kesehatan tunas medika. Jurnal Pangan Kesehatan Dan Gizi, 1(1), 11-17.

Erdianto, S. D. (2009). Hubungan Antara Faktor Individu dan Faktor Lingkungan Dengan Kecenderungan Penyimpangan Perilaku Makan Pada Mahasiswi Jurusan Administrasi Perkantoran dan Sekretaris FISIP UI tahun 2009. Skripsi. Universitas Indonesia.

Grogan, S. (2008). Body Image: Understanding Body Dissatisfaction in Men, Women and Childern. New York: Psychology Pers.

Husna, Asmaul. (2013). Perbedaan tingkat kepatuhan pasien hemodialisa berdasarkan jenis kelamin

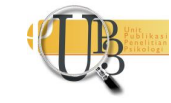


dalam mematuhi diet. Repository USU.

Husna, Nur Lailatul. (2013). Hubungan antara Body Image dengan Perilaku Diet: Penelitian pada Wanita di Sanggar Senam RITA Pati. Skripsi Fakultas Ilmu Pendidikan UNS. http://lib.unnes.ac.id/18410/1/1550406005.pdf

Ifdil, I., Denich, A., \& Ilyas, A. (2017). Hubungan Body Image dengan Kepercayaan Diri Remaja Putri. Jurnal Kajian Bimbingan dan Konseling. 2. 107-113. 10.17977/um001v2i32017p107.

Irawan, S., \& Safitri. (2014). Hubungan antara body image dan perilaku diet mahasiswi. Jurnal Psikologi, $12(1), 18-25$.

Mountford, V. \& Koskina, A. (2015). Body Image. 10.1007/978-981-287-087-2_74-1.

Muhith, A. (2015). Pendidikan Keperawatan Jiwa: Teori dan Aplikasi. Yogyakarta: Andi.

Naimah, T. (2008). Pengaruh komparasi sosial pada public figure di media massa terhadap body image remaja di kecamatan patikraja. Jurnal Psikologi Penelitian Humaniora, 9 (2).

Najam, N. \& Ashfaq, H. (2012). Gender differences in physical fitness, body shape satisfaction, and body figure preference. Pakistan Jurnal of Psychological Research, 27, 187-200.

Navia, B., Ortega, R. M., Requejo, A. M, Mena, M. C., Perea, J. M., \& López-Sobaler, A. M. (2003). Influence of the desire to lose weight on food habits, and knowledge of the characteristics of a balanced diet, in a group of Madrid university students. Eur J Clin Nutr 57, S90-S93. https://doi.org/10.1038/sj.ejcn.1601807

Neuman, W. (2007). Basics of Social Research Methods: Qualitative and Quantitative Approaches. Boston: Allyn.

Papalia, D. E., \& Olds, S. W. (2009). Human development 2. Jakarta: Salemba Humandika.

Polivy, J., \& Herman , C. P. (1978). Internal and external components of emotionality in restrained and undrestrained eaters. Journal of Abnormal Psychology, 87(5), 497-504.

Rombe, Sufrihana. (2013). Hubungan body image dan kepercayaan diri dengan perilaku konsumtif pada remaja putri di sma negeri 5 samarinda. PSIKOBORNEO: Jurnal Ilmiah Psikologi, 1 (4)

Siregar, M. H. (2009). Diet Efektif Berdasarkan Golongan Darah Anda. Yogyakarta: Buku Biru.

Yulianti, T. S., \& Indriati, R. (2015). Hubungan body image dengan perilaku diet pada remaja putri kelas xi ipa 3 dan 4 sma n 1 polanharjo klaten. Jurnal Keperawatan Intan Husada, 1(1), 57-66. Diakses dari http://stikeswh.ac.id:8082/journal/index.php/jners/article/view/123/114 